material in the general report is now only of historical interest, as conditions have changed radically since 1931. The report contains an account of the machinery of the Census, together with a discussion of some of the more important general results and an account of some minor inquiries, such as the number of Welsh-speaking persons in Wales, and the distribution of the alien population. Most of the figures in this volume have already appeared in previous Census publications, but the staff of the General Register Office have performed the task of summarizing and condensing the information with their usual lucidity.

\section{Metabolism of Humming-birds}

By measuring oxygen consumption, Oliver $P$. Pearson has calculated the rate of metabolism of humming-birds at rest and in flight and their energy needs over a 24-hour period (Condor, 52, No. 4; July-August 1950). Five anna (Calypte anna) and two allen (Selasphorus sasin sasin) humming-birds were studied and, resting in day-time, their rate of oxygen consumption was found to be higher than that of any other animal measured under comparable conditions. This high rate is in part balanced in both species by a period of torpidity at night, during which body temperature falls and oxygen consumption decreases to a significantly low rate. In captivity recovery from torpidity occurred spontaneously before daybreak; a peculiar feature was that torpidity did not occur in young anna humming-birds. Pearson also investigated the non-stop flight range of humming birds and showed that the maximum flight-range of the ruby-throated humming-bird, a migratory species suspected of making long over-water flights, is 385 miles.

\section{India Section of the Electrochemical Society}

Tre Electrochemical Society, Inc. (235 West 102nd Street, New York 25), is an organisation in the United States which was founded in 1902 to promote the advancement of electrochemistry, electrometallurgy, electrothermics, electronics and allied subjects. A section for India of this Society has been recently organised with headquarters at Bangalore, this being the first Section to be formed outside the United States. The officers of the Section are : Chairman, Dr. B. K. Ram Prasad, special officer, Electric Grid Offices, Government of Bombay, Bombay; Vice-Chairman, Dr. K. L. Ramaswamy, deputy production superintendent, Government of India Fertiliser Factory, Sindhri, and Mr. J. Balachandra, lecturer in electrometallurgy, Indian Institute of Science, Bangalore; Secretary-Treasurer, Dr. T. L. Rama Char, lecturer in electrochemistry, Indian Institute of Science, Bangalore. The inaugural meeting of the Section was held during March 23-24 at the Indian Institute of Science, Bangalore, and was well attended by scientific workers, engineers, industrialists and others interested in the future of electrochemistry in India. Dr.-B. K. Ram Prasad delivered the inaugural address and spoke on "Some Aspects of the Development of Electrochemical Industries in India". He indicated that there are great possibilities for the development of these industries, keeping in view the availability of raw materials, present output of electric power and future power development plans. Dr. Prasad said that he felt glad that the Government of India had decided to establish an Electro-Chemical Research Institute at Karaikudi, and expressed the hope that the Planning
Commission recently set up by the Government would consider in detail the development of electro. chemical industries in India.

\section{Electronics for Spectroscopists}

THE second annual summer school on electronics for spectroscopists, sponsored by the Photoelectric Spectrometry Group, which was held during July 8-15, was again organised at University College, Southampton. Mr. C. G. Cannon was organising secretary on behalf of the Group. The syllabus of the course placed emphasis on electronic techniques used in all aspects of spectroscopy. Lectures and demonstrations given by Prof. E. E. Zepler, S. W. Punnett, T. B. Tomlinson and G. H. Johns (Department of Electronics), included amplifier theory, effects of feedback, design of selective amplifiers, D.c. amplifiers, sources of noise and the calculation of noise in eircuits, stabilized power supplies, and general consideration of circuit design, testing and fault finding. Prof. A. M. Taylor gave a discourse on the "Optics of Spectrometerg", which included illumination of entrance slit-collimator systems; errors to finite slit-widths, and the choice of slitwidth; polarization by spectrographs ; and problems of 'lining up' and focusing. Two invited speakers contributed lectures on specialized subjects : Dr. A. Elliott (Courtaulds, Ltd., Maidenhead) spoke on the theory, use and experimental techniques of polarized infra-red radiation; and Dr. E. F. Daly (Unicam Instruments, Cambridge) lectured on the theory, mechanics and electronics of fast scanning of spectra, and on double-beam fast scanning with cathode ray tube presentation. There were three visitors from overseas: Dr. E. Kuyper (Royal Dutch Sholl, Amsterdam): Mr. F. Woutman (C.I.M., Delft); and Dr. M. Sanz (Dr. A. Wander S.A., Berne).

\section{Polish Academy of Science and Letters}

THE nineteenth annual publication of the Nature Protection Committee of the Polish Academy of Science and Letters contains English summaries of all articles. Among these is one by Jan Zabiński describing the work done in Poland since 1945 to save the European bison from extinction. The work has been initiated by the Bureau of Nature Protection, which, besides setting aside reserves ire Poland, each year assigns a certain number of animals for exchange with other countries interested in the problem of bison protection. Through Polish activity in the last four years two breeding centres have been established in the U.S.S.R. and one in Denmark; it is hoped that breeding centres will also be developed in Belgium, Switzerland and, perhaps, Czechoslovakia. Other articles include one by Aleksander Kosiba on problems of Nature protection in the Arctic; Jan Walas on the edelweiss; Jan Boguslaw Szczepski on the biology of the mallard; and Roman J. Wojtusiak on extinct and vanishing mammals.

\section{International Collection of Cytological Preparations}

AN International Collection of Cytological Preparations, under the auspices of the International Union of Biological Sciences, is housed in the Carnoy Institute at Louvain, Belgium. The Collection is in the charge of Prof. P. Martens, director of the Institute. Cytologists of all countries are invited to deposit in the Collection some of the slides which have served as the basis of their published researches. More than 8,000 preparations have already been assembled. 